\title{
Gain Scheduled Multivariable Control of a Continuous Stirred Tank Reactor
}

\author{
N. Kamala， J. Venkatesh Balaji
}

\begin{abstract}
Most chemical reactors, representing Multi-Input Multi-Output (MIMO) systems, are highly nonlinear and require complex control than single-input single-output (SISO) systems. In the present work, the system is linearized around different operating points. As linear design strategies are intended to work in linear regions, they are employed to evaluate local controller parameters. Decentralized controllers using constant detuning factor and decoupling controllers using static decouplers are designed. A gain scheduler is developed to deal with changes in operating conditions. The performances are evaluated by simulating the nonlinear equations of the system. Decentralized controllers cannot mitigate the interactions due to its structure possessing single loop. It is exhibited that the decoupling controllers offer better control for tracking of desired set point and rejection of load disturbances than those of decentralized controllers. The superiority of the suggested controller has been portrayed by performing simulation study on a Continuous Stirred Tank Reactor (CSTR).
\end{abstract}

Keywords: CSTR, decoupling control, decentralized control, Integral Absolute Error (IAE), Integral Square Error (ISE), gain schedule.

\section{INTRODUCTION}

$\mathrm{P}_{\mathrm{D}}$ controllers are the most popular and commonly employed industrial controllers in the past decades due to their simple design and ease of control. Several approaches [1] for optimum setting of PID controllers were suggested. The basic PID controllers have difficulty in controlling the processes with complex nonlinearity. If a fixed gain controller is utilized, it cannot control the system effectively with varying parameters and require frequent online retuning of controller gains. Gain scheduling approach, representing adaptive control with a set of controllers and a scheduler, is widely employed for controlling highly nonlinear systems. The scheduler will make its decision based on variables such as states, inputs, measured disturbances, auxiliary variables etc., In last several decades, the design of controllers for Multiple-input Multiple-output (MIMO) systems has become a major research topic among the researchers [2-5].

Decentralized control is employed for multivariable process control, when the process interactions are negligibly small [6]. Each pair of input and output requires tuning and controlling by individual controllers. If the interactions are large, centralized control system is employed. The interactions can be measured through employing relative gain array (RGA)[7-9].

Revised Manuscript Received on December 04, 2019

* Correspondence Author

N. Kamala, Department of Robotics and Automation, Jain (Deemed-to-be) University, Bangalore, India

Email: kamalajai216@gmail.com

J. Venkatesh Balaji, Department of Mechanical Engineering, MNM Jain Engineering College, Chennai, India.

Email: venkateshbalajijaikumar@gmail.com

The procedure for detuning method of Decentralized control:

- Neglecting the interactions, each individual controller is tuned.

- Measuring and accounting the interactions, the controller is detuned with a view of meeting the stability criterion. During operations, the controller may still require retuning. The parameter variation of a loop may deteriorate the performance of the others and affect the stability of the whole system. Most of the controllers are therefore loosely tuned with a view of ensuring the stability, which however makes the control inefficient and incurs larger energy costs Besides, retuning is a time consuming procedure. To overcome these difficulties decoupling controllers are considered for highly interacting processes [10-12].

In this paper, multivariable control of a Two-input Two-output CSTR is discussed. The feed and coolant flows are treated as inputs, while effluent concentration and reactor temperature are considered as outputs. While designing a decentralized controller, the input-output pairs are appropriately chosen in order to weaken the interactions. Gain scheduling is a widely used industrial control [15-16] when a plant is subjected to large changes in its operating state. As abrupt variations in the operating state may significantly alter the controller parameters, it may not be possible to devise a controller to operate satisfactorily at all operating points without demanding parameters retuning. Besides, it deteriorates the closed loop performance, as it cannot follow the operating state variations. In this work, the design of each PID controller in the decentralized control system is performed through IMC based PID tuning approach [13]. The decouplers and the PID controllers of a decoupling control system are designed using IMC tuning method [14]. The local models are interpolated using a gain scheduler. The performances of both the controllers are compared qualitatively and quantitatively.The paper is partitioned into $\mathrm{V}$ sections. Section II explains the description of the process and modeling the CSTR from first principles. Design of Controllers for the CSTR is presented in section III,section IV deals with results and discussions, Conclusions are presented in section $\mathrm{V}$.

\section{PROCESS DESCRIPTION}

CSTR, a highly nonlinear process, is popularly employed in chemical and petrochemical industries. A jacketed CSTR is either endothermic or exothermic which needs the heat to be added or removed in accordance with the difference between the temperatures of jacket and reactor fluids Usually, the heat transfer liquid is circulated via the jacket at a high velocity 
The standard two states CSTR model describing an irreversible exothermic reaction $\mathrm{A} \rightarrow \mathrm{B}$ is considered for the study. It is described by the differential equations (1) and (2) as follows:

$$
\begin{array}{r}
\frac{d C_{A}}{d t}=\frac{q}{V}\left(C_{A 0}-C_{A}\right)-k_{0} C_{A} \exp \left(\frac{-E}{R T}\right) \\
\frac{d T}{d t}=\frac{q}{V}\left(T_{0}-T\right)+\left(\frac{-\Delta H}{\rho C_{p}}\right) k_{0} C_{A} \exp \left(\frac{-E}{R T}\right) \\
+\left(\frac{\rho_{c} C_{p c}}{\rho C_{p} V}\right) q_{c}\left[1-\exp \left(\frac{-h A}{q_{c} \rho_{c} C_{p c}}\right)\right]\left(T_{0}-T\right)
\end{array}
$$

Table- I: Parameters of Jacketed CSTR

\begin{tabular}{|c|c|c|}
\hline Symbols & Parameters & Values \\
\hline $\mathrm{hA}$ & Heat transfer term & $7 \times 10^{5} \mathrm{cal} / \mathrm{min} \mathrm{K}$ \\
\hline $\mathrm{C}_{\mathrm{A} 0}$ & Feed concentration & $1 \mathrm{~mol} / \mathrm{l}$ \\
\hline $\mathrm{V}$ & CSTR volume & $100 \mathrm{l}$ \\
\hline $\mathrm{E} / \mathrm{R}$ & Activation energy term & $1 \times 10^{4} \mathrm{~K}$ \\
\hline $\mathrm{T}_{\mathrm{i}}$ & Reactor temperature & $441.2 \mathrm{~K}$ \\
\hline $\mathrm{q}_{\mathrm{C}}$ & Coolant flow rate & $100 \mathrm{l} / \mathrm{min}$ \\
\hline $\mathrm{C}_{\mathrm{A}}$ & Product concentration & $0.08823 \mathrm{~mol} / 1$ \\
\hline $\mathrm{q}$ & Process flow rate & $100 \mathrm{l} / \mathrm{min}$ \\
\hline $\mathrm{T}_{\mathrm{C} 0}$ & Inlet coolant temperature & $350 \mathrm{~K}$ \\
\hline $\mathrm{C}_{\mathrm{P}}, \mathrm{C}_{\mathrm{PC}}$ & Specific heat & $1 \mathrm{cal} / \mathrm{g} \mathrm{K}$ \\
\hline $\mathrm{K}_{0}$ & Reaction rate constant & $7.2 \times 10^{10} / \mathrm{min}$ \\
\hline $\mathrm{T}_{0}$ & Feed temperature & $350 \mathrm{~K}$ \\
\hline$\rho, \rho_{\mathrm{C}}$ & Liquid densities & $1 \times 10^{3} \mathrm{~g} / 1$ \\
\hline$\Delta \mathrm{H}$ & Heat of reaction & $-2 \times 10^{5} \mathrm{cal} / \mathrm{mol}$ \\
\hline & & \\
\hline
\end{tabular}

The parameters furnished in Table $\mathrm{I}$ are used for modelingthe Jacketed CSTR. In this model, the feed flow rate $\left(\mathrm{u}_{1}\right)$ and the coolant flow rate $\left(\mathrm{u}_{2}\right)$ are treated as the manipulated variables, while the effluent concentration $\left(\mathrm{y}_{1}\right)$ and the temperature of the reactor $\left(\mathrm{y}_{2}\right)$ are considered as the outputs. The effluent concentration $\left(\mathrm{x}_{1}\right)$ and the temperature of the reactor $\left(\mathrm{x}_{2}\right)$ are the considered as the states. For designing the controllers, the CSTR is linearized at three operating points and the values obtained are listed in Table II. The damping factor and the Eigen values corresponding to the chosen operating points are listed in Table III. It can be inferred from these values that the process is stable.

Table- II: Steady state operating points

\begin{tabular}{|c|c|c|c|c|}
\hline $\begin{array}{c}\text { Operating } \\
\text { point }\end{array}$ & $\begin{array}{c}\text { Feed Flow } \\
(\mathbf{l} / \mathbf{m i n})\end{array}$ & $\begin{array}{c}\text { Coolant } \\
\text { Flow } \\
(\mathbf{l} / \mathbf{m i n})\end{array}$ & $\begin{array}{c}\text { Conc } \\
(\mathbf{m o l} / \mathbf{l})\end{array}$ & $\begin{array}{c}\text { Temp } \\
(\mathbf{K})\end{array}$ \\
\hline 1 & 103 & 97 & 0.0748 & 445.3 \\
\hline 2 & 100 & 100 & 0.0882 & 441.2 \\
\hline 3 & 97 & 103 & 0.1055 & 436.8 \\
\hline
\end{tabular}

Table- III: Eigen values and damping factors

\begin{tabular}{|c|c|c|}
\hline Operating point & Eigen value & Damping factor \\
\hline 1 & $-3.08 \pm 2.85 \mathrm{i}$ & 0.733 \\
\hline 2 & $-1.98 \pm 3.06 \mathrm{i}$ & 0.544 \\
\hline 3 & $-1.05 \pm 2.91 \mathrm{i}$ & 0.340 \\
\hline
\end{tabular}

\section{DESIGN OF CONTROLLERS}

A. Design of Decentralized Controllers

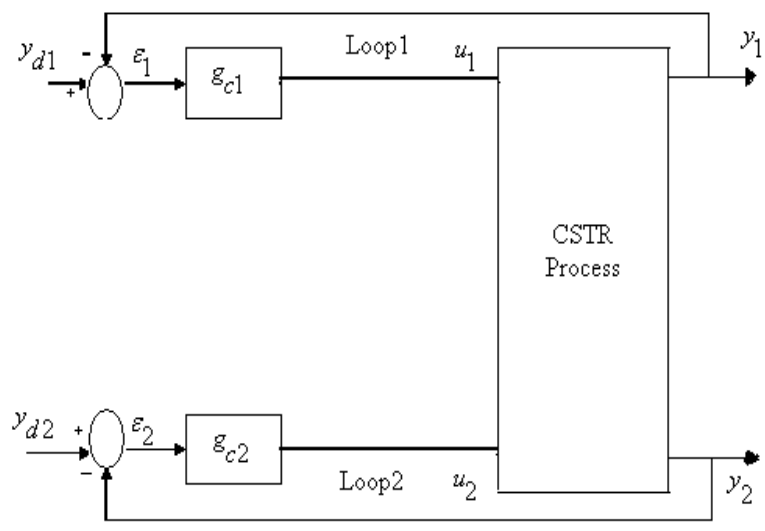

Fig. 1.Feedback control scheme for decentralized control

The feedback control scheme for multivariable process of decentralized control is shown in fig.1. To design a decentralized controller, the first step is to pair the input and output variables that can be obtained with the help of Relative Gain Array (RGA) [13]. The gain matrix of a Two-input Two-output system is formed as

$$
G(0)=\left[\begin{array}{ll}
G_{11}(0) & G_{12}(0) \\
G_{21}(0) & G_{22}(0)
\end{array}\right]=\left[\begin{array}{ll}
k_{11} & k_{12} \\
k_{21} & k_{22}
\end{array}\right] \text { (3) }
$$

The RGA can be built as

$$
\Lambda=\left[\begin{array}{cc}
\frac{k_{11} k_{22}}{k_{11} k_{22}-k_{12} k_{21}} & \frac{-k_{12} k_{21}}{k_{11} k_{22}-k_{12} k_{21}} \\
\frac{-k_{21} k_{12}}{k_{11} k_{22}-k_{12} k_{21}} & \frac{k_{11} k_{22}}{k_{11} k_{22}-k_{12} k_{21}}
\end{array}\right]=\left[\begin{array}{ll}
\lambda_{11} & \lambda_{12} \\
\lambda_{21} & \lambda_{22}
\end{array}\right]
$$

The RGA obtained at each operating point is given in Table IV. It is found that $\lambda_{11}$ is negative at all operating points. To avoid loops with negative relative gains, it is to be noted that input $\mathrm{y}_{1}$ and $\mathrm{y}_{2}$ should be paired with $\mathrm{u}_{2}$ and $\mathrm{u}_{1}$ respectively.

Table- IV: RGA at 3 operating states

\begin{tabular}{|c|c|}
\hline Operating point & RGA \\
\hline 1 & {$\left[\begin{array}{cc}-2.0871 & 3.0871 \\
3.0871 & -2.0871\end{array}\right]$} \\
\hline 2 & {$\left[\begin{array}{cc}-2.2722 & 3.2722 \\
3.2722 & -2.2722\end{array}\right]$} \\
\hline 3 & {$\left[\begin{array}{cc}-2.5998 & 3.5998 \\
3.5998 & -2.5998\end{array}\right]$} \\
\hline
\end{tabular}

Accordingly, in this work, effluent concentration and reactor temperature are controlled based on the coolant flow rate and the feed flow rate respectively, guided by RGA. The linearized models are determined by the linearization procedure at chosen operating points. 
The transfer function relating coolant flow with effluent concentration can be written as:

$$
\frac{\mathrm{k}_{\mathrm{p}}}{\tau^{2} \mathrm{~s}^{2}+2 \zeta \tau \mathrm{s}+1}
$$

By employing the technique suggested by Bequette (2001), the gain parameter of PI controller can be tuned as

$$
\begin{gathered}
\mathrm{K}_{\mathrm{c}}=\frac{2 \zeta \tau}{\mathrm{k}_{\mathrm{p}} \lambda} \\
\tau_{\mathrm{I}}=2 \zeta \tau
\end{gathered}
$$

The feed flow rate can be related by the following transfer function with reactor temperature as:

$$
\frac{\mathrm{k}_{\mathrm{p}}(-\beta \mathrm{s}+1)}{\tau^{2} \mathrm{~s}^{2}+2 \zeta \tau \mathrm{s}+1}
$$

The gain parameter can be tuned by adapting the IMC technique as

$$
\begin{aligned}
& \mathrm{K}_{\mathrm{c}}=\frac{2 \zeta \tau}{\mathrm{k}_{\mathrm{p}}(\beta+\lambda)} \\
& \tau_{\mathrm{I}}=2 \zeta \tau
\end{aligned}
$$

It is observed that the controller gain is a function of the filter parameter $\lambda$. The filter parameter values are chosen by a heuristic procedure and the selection of the appropriate filter parameter value is decided by the performance index measured in the closed loop.

Table- V: Parameters of decentralized control scheme

\begin{tabular}{|c|c|c|c|c|}
\hline \multirow{2}{*}{$\begin{array}{c}\text { Operating } \\
\text { point }\end{array}$} & \multicolumn{2}{|c|}{$\begin{array}{c}\text { Effluent } \\
\text { concentration control }\end{array}$} & \multicolumn{2}{|c|}{$\begin{array}{c}\text { Reactor temperature } \\
\text { Control }\end{array}$} \\
\cline { 2 - 5 } & $\boldsymbol{K}_{\boldsymbol{C}}$ & $\boldsymbol{K}_{\boldsymbol{I}}$ & $\boldsymbol{K}_{\boldsymbol{C}}$ & $\boldsymbol{K}_{\boldsymbol{I}}$ \\
\hline 1 & 44.8769 & 128.4768 & 0.1908 & 0.5461 \\
\hline 2 & 30.9472 & 103.7452 & 0.1136 & 0.3807 \\
\hline 3 & 17.7596 & 80.8726 & 0.0304 & 0.1385 \\
\hline
\end{tabular}

\section{B. Gain scheduler design (decentralized control)}

The output of gain scheduler is dependent on multiple local linear controllers. A method for dividing the operating region should be developed for blending the outputs of local controllers. The selection of variables is highly problem dependent. It can be noticed that the dynamic behavior significantly changes with the operating point of the CSTR system. The gain parameters for the chosen operating points are furnished in Table $\mathrm{V}$ and the controllers are switched among the chosen operating regions for controlling the system over the whole operating region.

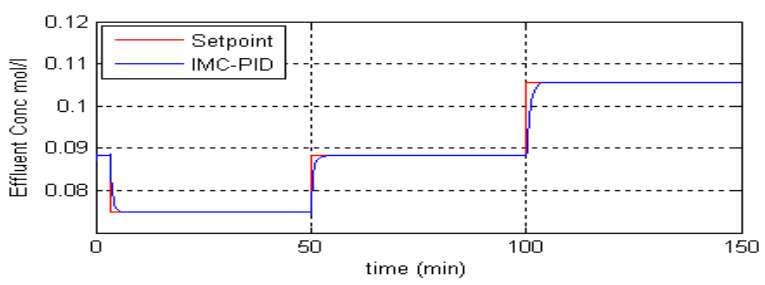

Fig.2.a.Response of Effluent concentration

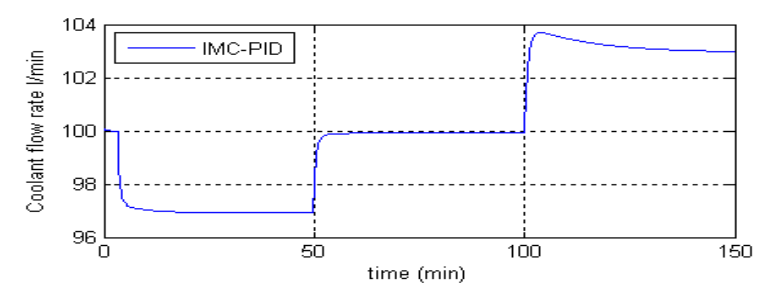

Fig.2.b.Response of coolant flow rate

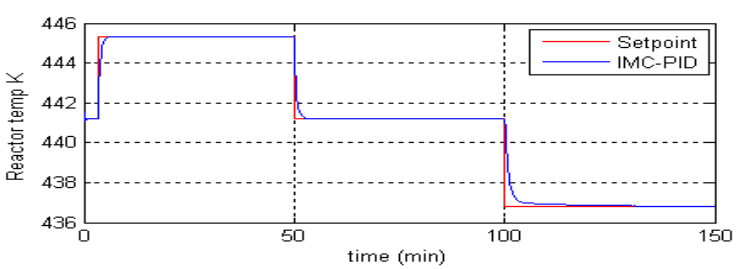

Fig.2.c.Response of reactor temperature

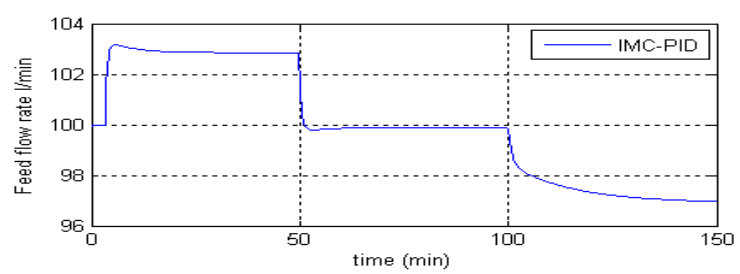

Fig.2.d.Response of feed flow rate

\section{Fig.2. Servo response of decentralized control scheme}

The simulations are performed on the decentralized controller with the obtained gain parameters of CSTR. The tracking capability of the developed PI controller can be assessed by varying the set point variations of effluent concentration and reactor temperature as given in Fig. 2.a and Fig.2.c. The changes in controller outputs are depicted in Fig. 2.b and Fig.2.d.

It can be observed from the responses that the CSTR with allocated gain can maintain the desired set point of reactor temperature and concentration.

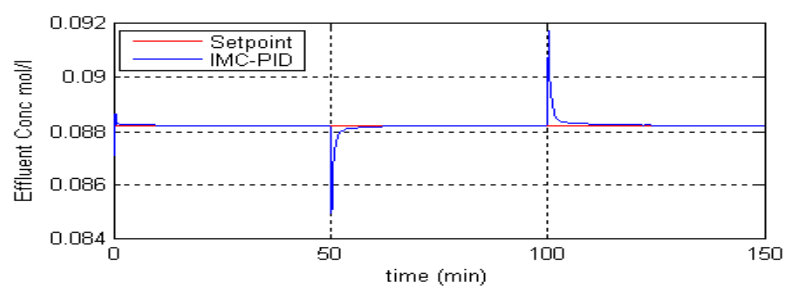

Fig.3.a.Response of effluent concentration

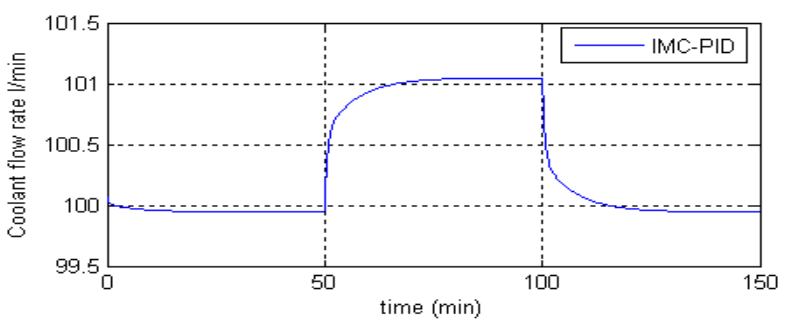

Fig.3.b. Response of coolant flow rate 


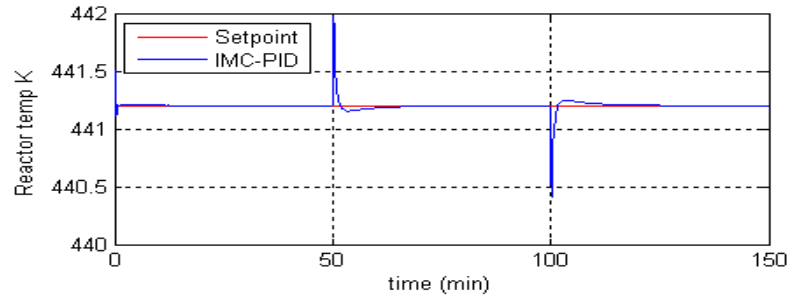

Fig.3.c. Response of reactor temperature

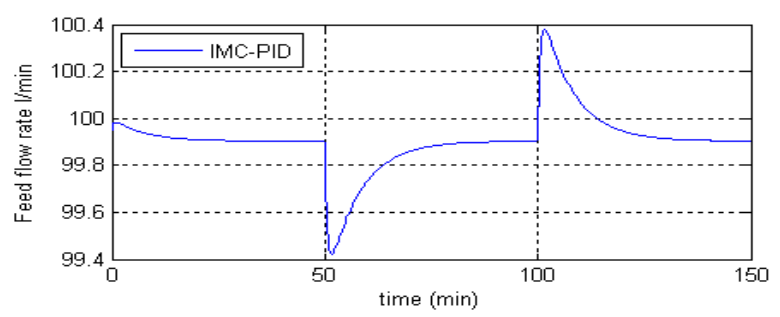

Fig.3.d. Response of feed flow rate

\section{Fig.3. Regulatory response of decentralized control scheme}

The ability of rejecting disturbances of the proposed controller has been tested by a +ve and -ve step inputs for temperature with a magnitude of $1 \mathrm{~K}$ at instants of $50 \mathrm{~min}$ and 100 min respectively. The changes in effluent concentration and reactor temperature are depicted in Fig. 3.a and Fig. 3.c respectively. The effects on controller outputs are displayed in Fig. 3.b and Fig. 3.d.It is seen from these figures that the proposed scheme has the ability to reject disturbances on loaded condition of the CSTR.

\section{Design of decoupling controllers}

The schematic of decoupled control scheme is shown in Fig. 4 for the multivariable control of CSTR. With a view of reducing the interaction due to cross coupling, decouplers are designed, followed by design of PI controllers for decoupled systems.

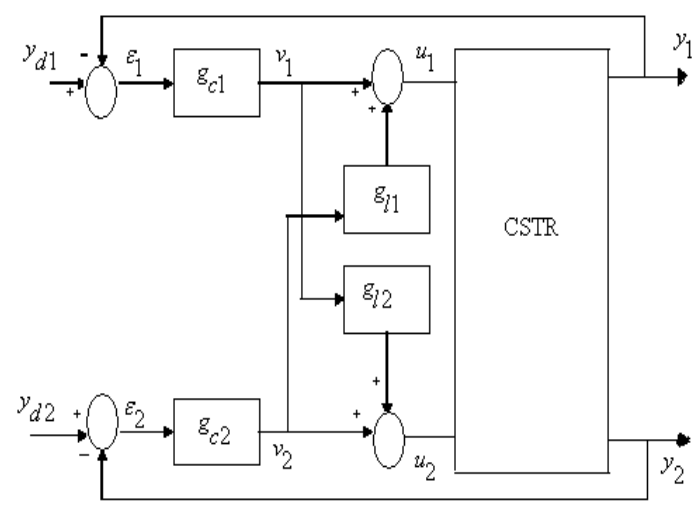

Fig.4. Decoupled control scheme for the CSTR

Table -VI: Static decouplers at chosen operating points

\begin{tabular}{|c|c|c|}
\hline Operating point & $\mathbf{g}_{\mathbf{1 1}}$ & $\mathbf{g}_{\mathbf{1}}$ \\
\hline 1 & 1.8577 & 0.7962 \\
\hline 2 & 1.7499 & 0.8229 \\
\hline 3 & 1.6416 & 0.8434 \\
\hline
\end{tabular}

The static decouplers are designed as follows:

$$
\begin{aligned}
& g_{11}=\frac{-g_{12}(0)}{g_{11}(0)} \\
& g_{12}=\frac{-g_{21}(0)}{g_{22}(0)}
\end{aligned}
$$

The presence of decouplers makes the multivariable system behave like two independent loops, thereby enabling the controllers to be designed independently. The static decouplers at chosen operating points are given in Table VI.

The equations for the two loops of a $2 \times 2$ multivariable system including the decouplers are given by

$$
\begin{array}{r}
\mathrm{y}_{1}=\left(\mathrm{g}_{11}-\frac{\mathrm{g}_{12} \mathrm{~g}_{21}}{\mathrm{~g}_{22}}\right) \mathrm{v}_{1}(9) \\
\mathrm{y}_{2}=\left(\mathrm{g}_{22}-\frac{\mathrm{g}_{12} \mathrm{~g}_{21}}{\mathrm{~g}_{11}}\right) \mathrm{v}_{2}(10)
\end{array}
$$

The controllers are designed by substituting the values of $\mathrm{g}_{\mathrm{ij}}$ in equations (9) and (10), and employing IMC based tuning approach. The PI controller parameters obtained at different operating points are furnished in Table VII.

Table- VII: Parameters of decoupled control scheme

\begin{tabular}{|c|c|l|l|c|}
\hline & \multicolumn{2}{|c|}{$\begin{array}{c}\text { Effluent } \\
\text { concentration control }\end{array}$} & $\begin{array}{c}\text { Reactor temperature } \\
\text { control }\end{array}$ \\
\hline $\begin{array}{c}\text { Operating } \\
\text { point }\end{array}$ & $\boldsymbol{K}_{\boldsymbol{C}}$ & $\boldsymbol{K}_{\boldsymbol{I}}$ & $\boldsymbol{K}_{\boldsymbol{C}}$ & $\boldsymbol{K}_{\boldsymbol{I}}$ \\
\hline 1 & 123.42 & 354.339 & 1.8359 & 5.2559 \\
\hline 2 & 137.1404 & 459.5857 & 1.359 & 4.487 \\
\hline 3 & 154.2477 & 702.083 & 0.808 & 3.678 \\
\hline
\end{tabular}

\section{Gain scheduler design (decoupled control)}

In this sub-section, the design of proposed controller settings at different operating points is discussed to provide a complete control during the whole operating region of the process. The responses are obtained by switching the chosen operating points. The following section discusses the simulation results obtained by using decoupled control scheme.

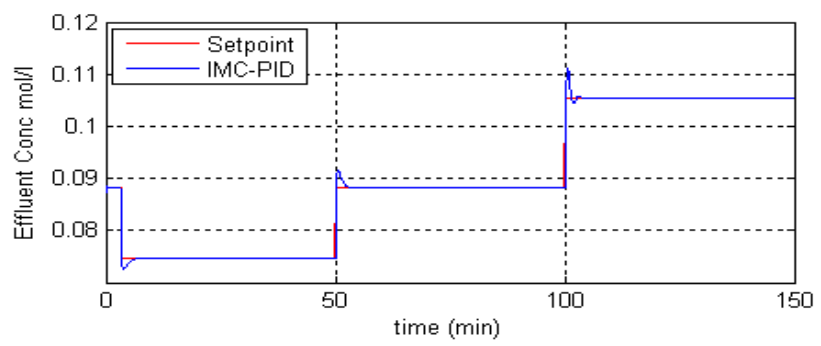

Fig.5.a. Response of effluent concentration

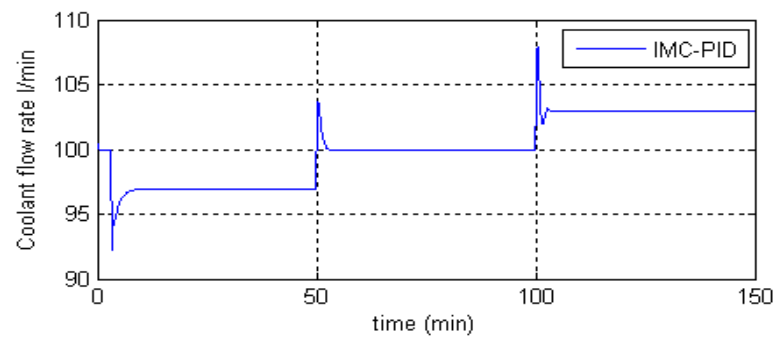

Fig.5.b. Response of coolant flow rate 


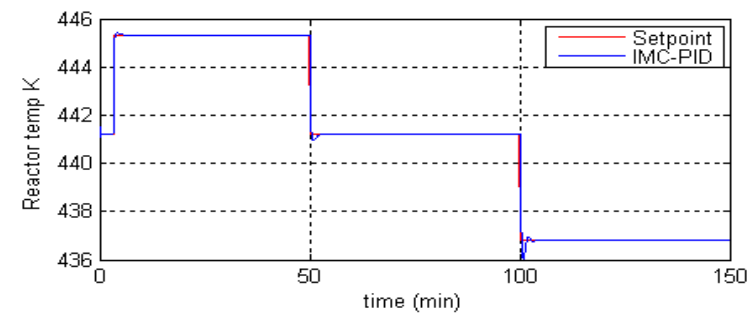

Fig.5.c. Response of reactor temperature

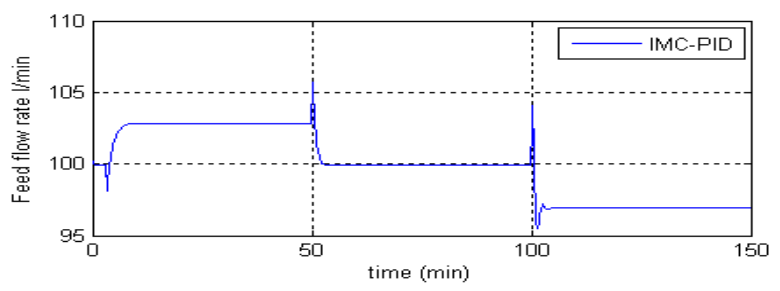

Fig.5.d. Response of feed flow rate

\section{Fig.5.Servo response of decoupled control scheme}

The simulations are performed on the proposed decoupled controller with the obtained gain parameters. The tracking capability of the developed PI controller can be assessed by varying the set point variations of effluent concentration and reactor temperature as given in Fig.5.a and Fig. 5.c. The changes in controller outputs are depicted in Fig. 5.b and Fig. 5.d.It can be observed from the responses that the decoupled controller with allocated gain can maintain the desired set point of reactor temperature and concentration.The performance of the decoupled controller is better than that of the decentralized controller for CSTR.

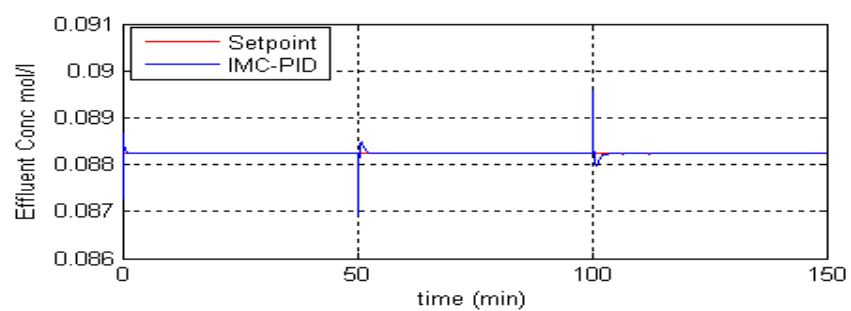

Fig.6.a. Response of effluent concentration

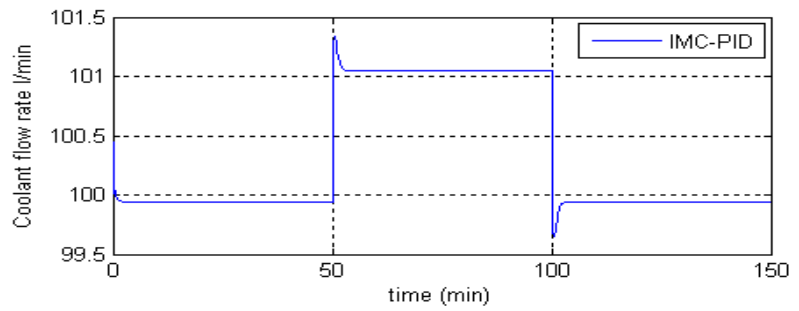

Fig.6.b. Response of coolant flow rate

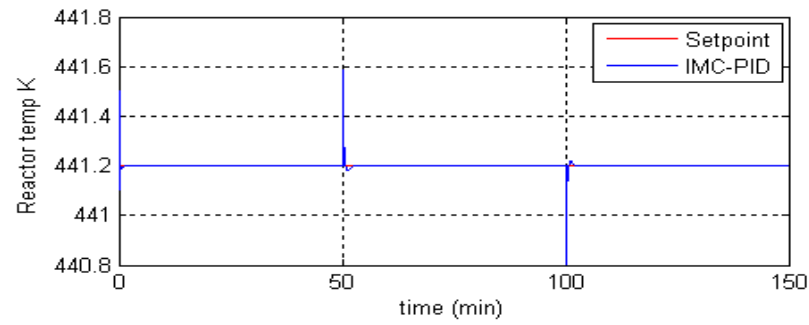

Fig.6.c. Response of reactor temperature

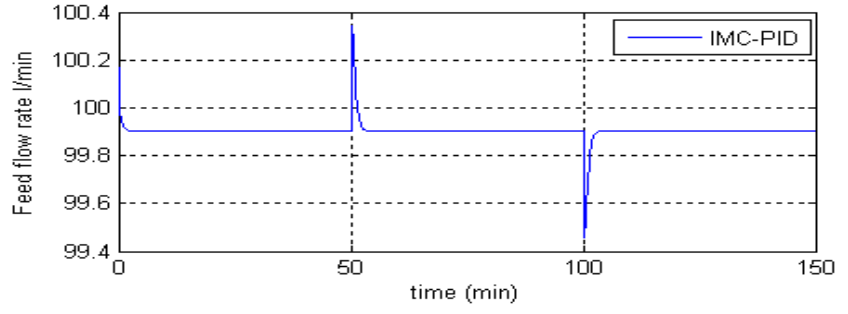

Fig.6.d. Response of feed flow rate

Fig. 6 Regulatory response of decoupled control scheme

The ability of rejecting disturbances of the proposed decoupled controller has been tested by a +ve and -ve step inputs for temperature with a magnitude of $1 \mathrm{~K}$ at instants of $50 \mathrm{~min}$ and $100 \mathrm{~min}$ respectively. The changes in effluent concentration and reactor temperature are depicted in Fig. 6.a and Fig. 6.c respectively. The effects on controller outputs are displayed in Fig. 6.b and Fig.6.d. It is seen from these figures that the proposed decoupled controller can reject disturbances on loaded condition of the CSTR.

\section{RESULT AND DISCUSSION}

In the simulation study conducted on the nonlinear CSTR, the state variables are evaluated by solving the nonlinear differential equations. Table VIII and Table XI provide the performance measures for servo and regulatory problems respectively using decentralized control scheme.

Table $\mathrm{X}$ and Table XI provide the performance measures for servo and regulatory problems respectively using decoupled controllers. The comparison of the performance measures such as IAE and ISE values between the decentralized and decoupled control schemes show that the performance is better with the decoupled controllers than with the decentralized controllers

Table- VIII: Performance measures for servo problem using decentralized controller

\begin{tabular}{|c|c|c|c|c|c|}
\hline $\begin{array}{c}\text { SI. } \\
\text { No. }\end{array}$ & $\begin{array}{c}\text { Time } \\
\text { interval } \\
(\mathbf{m i n})\end{array}$ & $\begin{array}{c}\text { IAE } \\
\text { Effluent } \\
\text { Conc. }\end{array}$ & $\begin{array}{c}\text { ISE } \\
\text { Effluent } \\
\text { Conc. }\end{array}$ & $\begin{array}{c}\text { IAE } \\
\text { Reactor } \\
\text { Temp }\end{array}$ & $\begin{array}{c}\text { ISE } \\
\text { Reactor } \\
\text { Temp }\end{array}$ \\
\hline 1. & $0-5$ & 0.0011 & $5.583 \mathrm{e}-7$ & 0.2161 & 0.0298 \\
\hline 2. & $5-50$ & 0.0239 & 0.0001 & 6.497 & 11.97 \\
\hline 3. & $50-100$ & 0.0475 & 0.0003 & 12.56 & 22.91 \\
\hline 4. & $100-150$ & 0.1039 & 0.0007 & 34.64 & 52.82 \\
\hline
\end{tabular}

Table- IX: Performancemeasures for regulatory problem using decentralized controller

\begin{tabular}{|l|l|l|l|l|l|}
\hline $\begin{array}{l}\text { Sl. } \\
\text { No. }\end{array}$ & $\begin{array}{l}\text { Time } \\
\text { interval } \\
\text { (min) }\end{array}$ & $\begin{array}{l}\text { IAE } \\
\text { Effluent } \\
\text { Conc. }\end{array}$ & $\begin{array}{l}\text { ISE } \\
\text { Effluent } \\
\text { Conc. }\end{array}$ & $\begin{array}{l}\text { IAE } \\
\text { Reactor } \\
\text { Temp }\end{array}$ & $\begin{array}{l}\text { ISE } \\
\text { Reactor } \\
\text { Temp }\end{array}$ \\
\hline 1. & $50-100$ & 0.0121 & $1.362 \mathrm{e}-5$ & 2.909 & 0.6551 \\
\hline 2. & $100-150$ & 0.0228 & $2.756 \mathrm{e}-5$ & 5.421 & 1.295 \\
\hline
\end{tabular}

Table- X: Performance measures for servo problem using decoupled control scheme

\begin{tabular}{|c|c|c|c|c|c|}
\hline $\begin{array}{c}\text { Sl. } \\
\text { No. }\end{array}$ & $\begin{array}{c}\text { Time } \\
\text { interval } \\
\text { (min) }\end{array}$ & $\begin{array}{c}\text { IAE } \\
\text { Effluent } \\
\text { Conc. }\end{array}$ & $\begin{array}{c}\text { ISE } \\
\text { Effluent } \\
\text { Conc. }\end{array}$ & $\begin{array}{c}\text { IAE } \\
\text { Reactor } \\
\text { Temp }\end{array}$ & $\begin{array}{c}\text { ISE } \\
\text { Reactor } \\
\text { Temp }\end{array}$ \\
\hline 1. & $0-5$ & 0.0006 & $2.874 \mathrm{e}-7$ & 0.132 & 0.0164 \\
\hline
\end{tabular}




\begin{tabular}{|l|l|l|l|l|l|}
\hline 2. & $5-50$ & 0.0131 & $3.714 \mathrm{e}-5$ & 1.585 & 2.186 \\
\hline 3. & $50-100$ & 0.0286 & $9.312 \mathrm{e}-5$ & 3.806 & 5.439 \\
\hline 4. & $100-150$ & 0.0487 & $2.075 \mathrm{e}-4$ & 7.958 & 11.8 \\
\hline
\end{tabular}

Table- XI: Performance measures for regulatory problem using decoupled control scheme

\begin{tabular}{|l|l|l|l|l|l|}
\hline $\begin{array}{l}\text { Sl. } \\
\text { No. }\end{array}$ & $\begin{array}{l}\text { Time } \\
\text { interval } \\
\text { (min) }\end{array}$ & $\begin{array}{l}\text { IAE } \\
\text { Effluent } \\
\text { Conc. }\end{array}$ & $\begin{array}{l}\text { ISE } \\
\text { Effluent } \\
\text { Conc. }\end{array}$ & $\begin{array}{l}\text { IAE } \\
\text { Reactor } \\
\text { Temp }\end{array}$ & $\begin{array}{l}\text { ISE } \\
\text { Reactor } \\
\text { Temp }\end{array}$ \\
\hline 1. & $50-100$ & 0.0024 & $1.285 \mathrm{e}-6$ & 0.5045 & 0.1011 \\
\hline 2. & $100-150$ & 0.0042 & $2.312 \mathrm{e}-6$ & 0.8785 & 0.1867 \\
\hline
\end{tabular}

\section{CONCLUSION}

Decoupled and decentralized MIMO controllers were designed for CSTR in this paper. RGA was applied for pairing the input-out variables. The pairs (effluent concentration-coolant flow) and (reactor temperature-feed flow) were identified to obtain superior performance. The IMC was applied for tuning the diagonal parameter of the decentralized controllers. Three operating points were chosen, and the gain parameters were switched to realize control over the whole operating region. Accounting the process interactions, the decoupled controller was designed by employing static decoupling strategy with a view of enhancing the performance. The simulations were performed to study the responses of the developed controllers. The qualitative and quantitative comparison of the closed loop simulation studies conducted on the CSTR using decentralized and decoupled control schemes reveal that the decoupling control scheme offers superior tracking of set points and rejection of load disturbances than that of decentralized controllers.

\section{REFERENCES}

1. Astrom K.J, Hagglund T, "PID controllers: Theory, designand tuning", Instrument society of America,2nd edition (1995)

2. Xiong Q., W.J.Cai, M.J.He 2007, "Equivalent transfer function method for PI/PID controller design of MIMO processes",Int.journal of Process control, 17, pp665-673

3. M.W.Iruthayarajan,S.Bhaskar, "Evolutionary algorithms based design of multivariable PID controller",Expert systems with Applications,36, 2009, pp 9159-9167

4. Koivo, H.N. and J.T.Tanttu, "Tuning of PID controllers: survey of SISO and MIMO techniques, preprint of IFAC International symposium on intelligent tuning and adaptive Control session, Singapore, 1991

5. Qiang Xiong, Wen-Jian Cai, Ming He, "A practical Decentralized PID Auto tuning Method for TITO systems under closed loop control", International Journal of Innovative computing, Information and Control.vol 2, number 2, April 2006

6. Lee,J.W.Cho and T.F.Edgar, "Multiloop PI controller tuning for interacting multivariable processes", Computers and Chemical Engineering,vol.22,pp.1711-1723,1998

7. J.Lee, T.Edgar," Interaction measure for decentralized control of multivariable process", Proc of American Control Conference, Anchorage, AK, 2002, pp 454-458

8. Bristol,E.h,"On a new measure of interaction for multivariable process control",IEEE Trans on Automatic control,1966,Vol.AC-11,pp 133-134

9. Glad,T.\&Ljung,L.ControlTheory-Multivariable and Nonlinear methods, Taylor and Francis, 2000, 467p, ISBN 0-7484-0878-9

10. Milanovic,J.V, \& Duque,A.C. "Identification of Electromechanical Modes and placement of PSSs Using Relative Gain array", IEEE Trans. On Power Systems,2004,Vol.19,pp 410-417

11. K.Astrom, Johansson, Wang, "Design of decoupled PID controllers for MIMO systems", Proc of American Control Conference, Arlington, VA 2001,pp 2015-2020
12. Tanttu, J.T., and Lieslehto,J, " A Comparative Study of Some Multivariable PI Controller Tuning Methods", IFAC Intelligent Tuning and Adaptive Control, Singapore, 1991, pp357-362

13. Skogestad, Postlethwaite.I: Multivariable Feedback Control, John Wiley\& Sons, New York, 1996

14. Ogunnaike, B.A, and Ray, W.H.: Process Dynamics, Modeling and Control, Oxford University Press, New York,1994

15. Astrom,K.J and Witten mark, B 2001.Adaptive control, Pearson Education Press, Boston

16. Rahul Upadhyay, Rajesh Singla, "Application of adaptive control in aprocess control", 2nd international conference on education technologyand computer (ICETE), 2010. (IEEE).

\section{AUTHORS PROFILE}

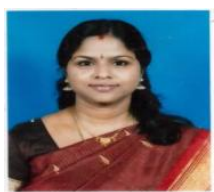

Dr.N.Kamala obtained her B.E in Electrical and Electronics Engineering and M.E in Power System from Annamalai University, Tamil Nadu. Her research interests in artificial intelligence applications in Multivariablecontrol system motivated her to obtain doctoral degree from Anna University under the guidance of Dr.T.Thyagarajan, Dean MIT, Chennai. She has published her research findings in various national, International conferences and International Journals. She is passionate about Machine Learning / AI applications to Robotics and Automation.She is a life member of ISTE, IAENG, IACRD. Currently she is working as Associate professor in the Department of Robotics and Automation at Jain (Deemed-to-be) University, Bangalore

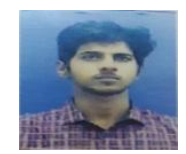

J.Venkatesh Balaji is a student of Mechanical Engineering at MNM Jain Engineering college Chennai. He has participated and organized various conferences and workshops at institutional level and presented projects at IIST, Trivandrum. He exhibited himself as a challenging leader and an Entrepreneur. He is currently working on modeling and design of Heat Exchanger. He is a member of ISA and IAENG. 